\title{
Can procalcitonin be a new biomarker in prostate cancer? Preliminary results
}

\author{
Abdullah Ilktac ${ }^{1}$, Senad Kalkan ${ }^{1}$, and Selahattin Çalı̧san ${ }^{2}$ \\ ${ }^{1}$ Bezmialem Vakif Universitesi Tip Fakultesi \\ ${ }^{2}$ Reyap Special Hospital
}

June 8, 2020

\begin{abstract}
Aim: Prostate cancer (PCa) is one of the most common cancer among men in the world. Prostate specific antigen is the most used biomarker for PCa diagnosis. In this study we aimed to measure the procalcitonin(PCT) and C-reactive protein (CRP) levels in patients with PCa. Methods: The patients who underwent transrectal prostate biopsy and transurethral prostate surgery in the last 4 years were included in the study. The patients were divided into two groups according to the pathology reports, group1; benign prostate hyperplasia and group2; prostate cancer. MedCalc Statistical Software version 17.6 was used for statistical analyses. Results: The current study includes 149 patients. There were 118 patients in group1 and 31 patients in group 2. The mean age of the patients was 66.85 and 69.41 years in groups respectively. Serum CRP and PCT levels was 3.33 and 0.01 in group 4.07 and 0.04 in group 2. Serum PCT levels was significantly higher in patients with PCa. Conclusion: We found that elevated procalcitonin levels was associated with prostate cancer. Further studies are needed to define the relationship between procalcitonin and prostate cancer. What's Known: Prostate cancer is the second most common cancer among elderly men. Prostate specific antigen testisng is usually used in screening and diagnosis. Unfortunately PSA is not cancer specific and new biomarkers are needed for prostate cancer management. What's New: Procalcitonin is a precursor of calcitonin which is produced by thyroid C-cells and some neuroendocrine cells. The elevated level of procalcitonin is associated with bacteremia and sepsis. In this study e investigated the procalcitonin levels in prostate cancer.
\end{abstract}

\section{C-reactive protein and Procalcitonin levels in Prostate Cancer}

Aim: Prostate cancer (PCa) is one of the most common cancer among men in the world. Prostate specific antigen is the most used biomarker for $\mathrm{PCa}$ diagnosis. In this study we aimed to measure the procalcitonin(PCT) and C-reactive protein (CRP) levels in patients with $\mathrm{PCa}$.

Methods: The patients who underwent transrectal prostate biopsy and transurethral prostate surgery in the last 4 years were included in the study. The patients were divided into two groups according to the pathology reports, group1; benign prostate hyperplasia and group2; prostate cancer. MedCalc Statistical Software version 17.6 was used for statistical analyses.

Results: The current study includes 149 patients. There were 118 patients in group1 and 31 patients in group 2. The mean age of the patients was 66.85 and 69.41 years in groups respectively. Serum CRP and PCT levels was 3.33 and 0.01 in group 4.07 and 0.04 in group 2. Serum PCT levels was significantly higher in patients with $\mathrm{PCa}$.

Conclusion: We found that elevated procalcitonin levels was associated with prostate cancer. Further studies are needed to define the relationship between procalcitonin and prostate cancer.

What's Known: Prostate cancer is the second most common cancer among elderly men. Prostate specific antigen testisng is usually used in screening and diagnosis. Unfortunately PSA is not cancer specific and 
new biomarkers are needed for prostate cancer management.

What's New: Procalcitonin is a precursor of calcitonin which is produced by throid C-cells and some neuroendocrine cells. Elevated level of procalcitonin is associated with bacteremia and sepsis. In this study e investigated the procalcitonin levels in prostate cancer.

Key Words: prostate cancer, procalcitonin, C-reactive protein

Introduction: Prostate cancer $(\mathrm{PCa})$ is one of the most common cancer among males in the world and the fifth most common malignancy in the general population (1). Serum prostate specific antigen (PSA) testing is the most commonly used test for the diagnosis and screening of $\mathrm{PCa}(2)$. The patients may be diagnosed as from clinically indolent to metastatic disease (3).Digital rectal examination (DRE) and PSA testing are important for early diagnosis of $\mathrm{PCa}$ (4). Unfortunatelly PSA is not cancer specific marker, it is organ specific; so elevated levels are seen in benign diseases such as prostatitis, benign prostate hyperplasia and urinary retention $(1,4)$.Despite its adequate sensitivity, the use of PSA testing is limited and additional serum testing derivated from PSA ( PSA density, free/total PSA, PSA velocity) and new biomarkers (prostatehealthindex, fourkallikrein and procalcitonin) were investigated for diagnosis of PCa $(2,4,5)$.

C-reactive protein (CRP) is an acute-phase proteinwhich is produced in the liver (6). High levels of CRP (1000 fold) are usually associated with microbial infection, trauma, infarction and autoimmun diseases. In addition, elevated CRP levels have been linked to poor prognosis in some malignancies; oral squamous cell carcinoma, esophagealcarcinoma, non-small and small cell lung cancers, melanoma, hepatocellular carcinoma, breast cancer, endometrial cancer, urogenital cancers. Procalcitonin (PCT) is produced by throid C-cells and some neuroendocrine cells and it is a precursor of calcitonin (2). In the systemic inflammatory reaction and some malignancies such as thyroid and renal cell carcinomas have an association with PCT levels. In this study, we aimed to measure CRP and PCT levels in prostate cancer patients and compared the patients without malignancy.

Methods: The patients who underwent transrectal prostate biopsy and transurethral prostate surgery between January 2016 and June 2019 were included in the study. The patients history of radiotherapy, dutasteride therapy, malignancy, chronic prostatitis and high level of PSA (>100 ng/ml) were excluded. The biopsy was made under local anesthesia with lateral decubitus position at least ten cores and prostate surgery was made under spinal or general anestesia with lithotomy position. The PSA, free PSA, CRP, PCT levels were measured before the procedures. After the pathological examination; the patients were divided into two groups. The patients with benign prostate hyperplasia was in Group 1 and PCa was in group 2. The results of high grade prostatic intraepithelial neoplasia (n:3) and atypical small acinar proliferation(n:4) were excluded from the study.

Distribution normality was analyzed with the Kolmogorov-Smirnov test. The normal distribution variable was compared with independent $t$ test and the others were compared with Mann-Whitney $U$ test. The chi squared test was used for percentage values. Data were expressed as mean \pm standard deviation for PSA, free PSA, CRP, PCT and sedimentation median for the age, neutrophil and white blood cell and $\mathrm{p}<0.05$ as considered with statistical significance. The receiver operating characteristic(ROC) curves were analyzed to assess the diagnostic utility total PSA,CRP and PCT levels in different PSA levels $(<10$ and $>10 \mathrm{ng} / \mathrm{ml}$ ). Statistical analyses were performed using the demo version of MedCalc Statistical Software version17.6 (MedCalc Software bvba, Ostend, Belgium; http:// www.medcalc.org; 2017).

Results: There were 149 patients in this study. Of these patients; 118 patients were in Group1 and 31 patients were in Group 2. The mean age of the patients was $66.85+8.19$ and $69.41+6.20$ years in groups respectively ( $\mathrm{p}=0.10$ ). Table 1 shows the patients' characteristics. The PSA level was significantly higher in group 2. Serum CRP and PCT levels was $3.3 \mathrm{mg} / \mathrm{L}$ and $0.01 \mathrm{ng} / \mathrm{ml}$ in group $1,4.07 \mathrm{mg} / \mathrm{L}$ and $0.04 \mathrm{ng} / \mathrm{ml}$ in group 2 ( $\mathrm{p}=0.08$ for $\mathrm{CRP}$ and $\mathrm{p}<0.05$ for $\mathrm{PCT}$ ).

The diagnosis was made by prostate biopsy in 92 patients and prostate surgery in 57 patients (Table-2). There was significant difference for diagnosis method in groups $(\mathrm{p}<0.05)$. In group 2; GS 6 and 7 was detected 
in 11 and 7 patients respectively. Gleason score was reported as 8,9 and 10 in7,4 and 2 patients.

Discussion: PCa is the most common malignancy in men older than 60 years and the second most common cause of cancer deaths after lung cancer in worldwide (7).The main cause of PCa is unknown but age, genetic factors, diet and environmental factors are focused on the etiology (8). Serum PSA testing is the most widely accepted and used biomarker for prostatic diseases especially PCa (9). But PSA is not cancer specific marker, increases in benign prostate diseases and there is no threshold value of PSA for cancer diagnosis(1). In general PSA over $4 \mathrm{ng} / \mathrm{ml}$ is recommended for biopsy, the cancer detection rate is between $20-25 \%$ in patients with a PSA value of $4-10 \mathrm{ng} / \mathrm{ml}$. In our previous study, the cancer detection rate was $22.3,34.5$ and $54.2 \%$ in patients with PSA level of 4-10, 10.01-20 and 20.01-50 ng/ml respectively(10). To reduce the unnecessary biopsies; new molecules and markers which have higher positive predictive value than PSA have been investigated (1). Prostate health index, four kallikrein score test, PSA density and velocity, free/total PSA ratio, PCA3 marker was used to differentiate benign prostate diseases from PCa(4). We found that free/total PSA ratio has significant diagnostic efficacy for PCa diagnosis in PSA level 4.01-10 ng/ml $(5)$.

C-reactive protein is an acutphase protein which is mainly produced in liver and rarely in atherosclerotic lesions, kidney, neurons and alveolarmacrophages in the body (11). Synthesis of CRP is associated with interleukin 6 (IL-6) secretion from macrophages and T-cells. In the inflammation;activation of IL-6 increases the serum level of CRP. Systemic inflammation has an important role in cancer initiation, promotion, progression, metastasis stimulates endocrine cells to hyperplasia and neoplastic transformation (12). C-reactive protein can predict the urological cancers such as renal cell carcinoma, bladder cancer, prostate cancer and upper urinary tract cancers. On the contrary the authors found no association between PCa risk and CRP levels(13). The authors demonstrated that CRP was a prognostic factor in PCa and correlated with patients who had bone metastasis than without metastasis (12).

Procalcitonin is a 116 amino-acid protein with a weight of $13 \mathrm{kDa}$ which is a precursor of the calcitonin hormone (14). During bacterial and fungal infections; circulating and cytokines increases the level of PCT and it has been investigated as a marker for bacteremia and sepsis $(14,15)$. The studies showed that inflammation plays an important role for tumorgenesis and relationship between PCT and medullary carcinoma and nunsmall cell lung cancer were investigated $(16,17)$. In addition, the authors reported that PCT value may be a biomarker for prediction of localized clearr cell carcinoma (15). The authors from Turkey found that PCT can be used to diagnose of PCa with a PSA level of 2-20 ng/ml (2). We found a high diagnostic efficacy of PCT in patients with a PSA level $>10 \mathrm{ng} / \mathrm{ml}$ and no significant difference between PSA and PCT.

There ara some limitations in the current study. This study includes a small number of patients from one center and the parameters (CRP, PCT) were not checked again after first measuring the levels. The stage of the patients with $\mathrm{PCa}$ was not homogenous.

We found that serum PCT levels were higher in patients with prostate cancer. If further studies support our findings serum PCT can be a new biomarker to diagnose prostate cancer in the future.

Funding: None

Acknowledgements : None

\section{REFERENCES}

1)Selvi I, Basar H, Baydilli N,Murat K, Kaymaz O. The importance of plasma arginine level and its downstream metabolites in diagnosing prostate cancer. Int Urol Nephrol. 2019; 51(11): 1975-1983.

2)Canat L, Atalay HA, Can O,Alkan I, Otunctemur A. Serum procalcitonin levels in prostate cancer: A new biomarker?. Urologia Journal.2018; 85(2):46-50.

3) Verep S,Erdem S, Ozluk Y,Kilicaslan I, Sanli O, Ozcan F. The pathological upgrading after radical prostatectomy in low-risk prostate cancer patients who are eligible for active surveillance: How safe is it to depend on bioptic pathology? Prostate. 2019;79(13):1523-1529. 
4) Ceylan C, Doluoglu OG, Yahşi S. A different perspective: Can urine $\mathrm{pH}$ be important in the diagnosis of prostate cancer?Urologia. 2019 Jul 31:391560319865724.

5)CaliskanS.Diagnostic efficacy of free prostate-specific antigen/total prostate-specific antigen ratio for the diagnosis of prostate cancer in low concentration ([?]4 ng/ml) and intermediate levels of total prostatespecificantigen (4.01-10.0ng/ml). J Can ResTher 2017;13:279-83.

6) Schnoeller TJ, Steinestel J, Steinestel K, Jentzmik F, Schrader AJ. Do preoperative serum C-reactive protein levels predict the definitive pathological stage in patients with clinically localized prostate cancer? $2015 ; 47(5): 765-70$.

7) Memis A, Ugurlu O, Ozden C, Oztekin CV, Aktas BK, Akdemir AO. The correlation among the percentage of positive biopsy cores from the dominant side of prostate, adverse pathology, and biochemical failure after radical prostatectomy. Kaohsiung J MedSci 2011;27:307-13.

8) Benli E, Cirakoglu A, Ayyıldı SN, Yüce A Comparison of serum uric acid levels between prostate cancer patients and a control group. Cent European J Urol. 2018;71(2):242-247.

9) Elzanaty S, Rezanezhad B, Borgquist R. Association between PSA Levels and Biomarkers of Subclinical Systemic Inflammation in Middle-Aged Healthy Men from the General Population.Curr Urol. 2016 Oct;9(3):148-152.

10)Çalışkan S. Prevelance of prostate cancer among Turkish men with prostate-specific antigen level of [?]100 ng/ml. J Can ResTher 2018;14:1256-9.

11)Schimmack S, Yang Y, Felix K, Herbst M, Li Y, Schenk M, Bergmann F, Hackert T, Strobel O. Creactive protein $(\mathrm{CRP})$ promotes malignant properties in pancreatic neuroendocrine neoplasms. Endocr Connect. 2019:8;1007-1019.

12) Dai J1, Tang K, Xiao W, Yu G, Zeng J, Li W, Zhang YQ, Xu H, Chen ZQ, Ye ZQ. Prognostic significance of C-reactive protein in urological cancers: a systematic review and meta-analysis.Asian Pac J Cancer Prev. 2014;15(8):3369-75.

13)Van Hemelrijck M, Jungner I, Walldius G, Garmo H, Binda E, Hayday A, Lambe M, Holmberg L, Hammar $\mathrm{N}$. Risk of prostate cancer is not associated with levels of C-reactive protein and other commonly used markers of inflammation. IntJ Cancer.2011:15;129(6):1485-92.

14) Sbrana A1, Torchio M2, Comolli G3, Antonuzzo A1, Danova M2; Italian Network for Supportive Care in Oncology (NICSO). Use of procalcitonin in clinical oncology: a literature review. New Microbiol. 2016 Jul;39(3):174-180.

15) Hamidi N, Gokce MI, Suer E, Baltacı S. Evaluation of increased preoperative serum high sensitive Creactive protein and procalcitonin levels on grade and stage of clear cell renal cell carcinoma. 2015;83(4):225230 .

16) Giovanella L, Verburg FA, Imperiali M, Valabre - ga S, Trimboli P, Ceriani L. Comparison of serum calcitonin and procalcitonin in detecting medul - lary thyroid carcinoma among patients with thy - roid nodules. Clin Chem Lab Med. 2013; 51: 1477-1481.

17) Walter MA, Meier C, Radimerski T, Iten F, Kränz - lin M, Müller-Brand J, de Groot JW, Kema IP, Links TP, Müller B. Procalcitonin levels predict clinical course and progression-free survival in patients with medullary thyroid cancer. Cancer. 2010; 116: 31-40.

\section{Hosted file}

tablo 1.docx available at https://authorea.com/users/330882/articles/457690-canprocalcitonin-be-a-new-biomarker-in-prostate-cancer-preliminary-results

\section{Hosted file}


table-2.docx available at https://authorea.com/users/330882/articles/457690-canprocalcitonin-be-a-new-biomarker-in-prostate-cancer-preliminary-results 